\title{
OS PROCESSOS MENTAIS COMO LEITMOTIVNA REPRESENTAÇÃO DO DINAMISMO SUBJETIVO DA NARRADORA EM INÉS DEL ALMA MÍA E NA TRADUÇÃO BRASILEIRA INÊS DE MINHA ALMA
}

\author{
MENTAL PROCESSES AS LEITMOTIFIN THE SUBJECTIVE \\ DYNAMISM REPRESENTATION OF THE NARRATOR IN INÉS \\ DEL ALMA MIIA AND IN THE BRAZILIAN TRANSLATION INÊS \\ DE MINHA ALMA
}

\section{Giovanna Marcella Verdessi Hoy* Adail Sebastião Rodrigues-Júnior ${ }^{* *}$}

\section{RESUMO}

O presente estudo objetiva mostrar a relevância dos Processos Mentais na representação do dinamismo subjetivo (HOY, 2017) da narradora e protagonista de Inés del alma mía (ALLENDE, 2006) e na tradução para o português brasileiro, especialmente quando compõem o eixo do pensamento, a partir de uma abordagem sistêmico-funcional (HALLIDAY; MATHIESSEN, 2014). De igual modo, pretende identificar as equivalências e mudanças ideacionais na tradução, com base na interface da Gramática Sistêmico-Funcional (GSF), dos Estudos da Tradução e do texto literário (CATFORD, 1965; MATTHIESSEN, 2001; HASAN, 1989; RODRIGUES-JÚNIOR; GARCIA de OLIVEIRA, 2015a; RODRIGUES-JÚNIOR; BARBARA, 2013). Para isso, utilizaram-se três ferramentas do programa computacional WordSmith Tools 6.0 para a extração dos dados, sua organização e descrição, quais sejam: i) a lista de palavras (word list); ii) o concordanciador (concordance), e; iii) o alinhador (View \& Aligner). Nos procedimentos de análise da representação ideacional e do dinamismo de Inés, empregaram-se as categorias do sistema de transitividade da GSF, bem como os conceitos de equivalência e mudança ideacional (RODRIGUES-JÚNIOR; GARCIA de OLIVEIRA, 2015a) e do eixo do pensamento. Os dados mostraram que os Processos Mentais foram recursos relevantes para a representação do dinamismo subjetivo (HOY, 2017) de Inés e que a equivalência ideacional prevaleceu no texto traduzido, apesar de terem sido identificadas mudanças ideacionais que modificaram a representação ideacional de Inés.

Palavras-chave: Tradução Literária; Transitividade; Eixo e Dinamismo Subjetivo.

\footnotetext{
* Universidade Federal de Ouro Preto (UFOP), Ouro Preto, MG, Brasil. giovannaverdessihoy@ yahoo.com.br

** Universidade Federal de Ouro Preto (UFOP), Ouro Preto, MG, Brasil. adail.sebastiao@gmail.com
} 


\section{ABSTRACT}

This study aims, from a systemic functional approach (HALLIDAY; MATHIESSEN, 2014), to show both in source text and target text (Brazilian Portuguese) the relevance of MENTAL PROCESSES, taken here as subjective dynamism (HOY, 2017), for the representation of the narrator and protagonist of Inés del alma mía (ALLENDE, 2006), especially when related to the axis of thinking. It also aims to identify the ideational equivalences and shifts in the target text based on the Transitivity model applied to literary translation (CATFORD, 1965; MATTHIESSEN, 2001; HASAN, 1989; RODRIGUES-JÚNIOR; GARCIA de OLIVEIRA, 2015a; RODRIGUES-JÚNIOR; BARBARA, 2013). The data were collected, organized and described by using three tools from the WordSmith Tools 6.0 software: (i) wordlist; (ii) concordance; (iii) and View and Aligner. The analysis procedures concerning Inés's ideational representation and her dynamism was carried out based on the Transitivity model and the concepts of ideational equivalence and shifts (RODRIGUES-JÚNIOR; GARCIA de OLIVEIRA, 2015a), as well as upon the axis of thinking. The data has shown that mental processes were considered relevant resources to represent Inés's subjective dynamism (HOY, 2017). It has also demonstrated that the ideational equivalence has prevailed in the target text, although there were some ideational sbifts that have changed her ideational representation.

Keywords: Literary Translation; Transitivity; Axis; Subjective Dynamism.

\section{INTRODUÇÃO}

Neste artigo, enfocam-se os Processos Mentais da Linguística SistêmicoFuncional (doravante LSF) na representação da narradora e de seu dinamismo subjetivo, Inés, no romance histórico Inés del alma mía da escritora chilena Isabel Allende (2006) e de sua tradução para o português brasileiro feita por Ernani Ssó (ALLENDE, 2007). Inés Suarez foi uma mulher do século XVI que teve participação fundamental na formação de Santiago e do Chile, cujos registros históricos não podem se esquivar de pelo menos citá-la, uma vez que suas ações são incontestáveis. Embora esteja nos registros históricos, nem toda a historiografia apresenta maiores aprofundamentos a respeito dessa mulher e de outras que tiveram participação da construção da história do Chile Colonial. Daí a importância do texto ficcional de Isabel Allende que coloca esta mulher ativa como protagonista e narradora dos fatos, desenvolvendo uma visão mais abrangente dessa importante mulher da história chilena.

Sabendo-se que os Processos Mentais são importantes recursos para representar experiências internas (HALLIDAY; MATTHIESSEN, 2014), aventouse a hipótese de que as experiências ficcionais internas da narradora não somente estejam relacionadas a um aspecto subjetivo, mas também a um dinamismo subjetivo (HOY, 2017) mediante o qual Inés seja capaz de afetar seu entorno. Outra hipótese que se colocou neste artigo é que, devido à proximidade das duas línguas, as escolhas tradutórias terão um alto índice de equivalências ideacionais na representação 
do dinamismo subjetivo de Inés, o que não exclui as escolhas linguísticas que trazem mudanças (shifts) ideacionais (RODRIGUES-JÚNIOR; GARCIA de OLIVEIRA, 2015a)

Não são muitas as pesquisas sobre os Processos Mentais, porém, alguns trabalhos foram identificados. Em 2006, Maria Medianeira de Souza realizou uma análise dos Processos Mentais e seus participantes no gênero editorial demonstrando como esses processos atuam na variação do gênero. A pesquisadora concluiu que esses processos são importantes recursos na construção da opinião no gênero editorial, uma vez que põem em relevo "desejos, sentimentos e saberes que reforçam o ponto de vista defendido no editorial" (SOUZA, 2006, p. 457).

Com base no texto literário, Andrade (2011) realiza um estudo de caso analisando a narrativa autobiográfica de um imigrante nos EUA, mediante a LSF em sua dissertação de Mestrado. Nesse estudo, Andrade (2011) objetivou analisar as escolhas léxico-gramaticais de Participantes, Processos e Circunstâncias na constituição da identidade do narrador. Ele concluiu que o narrador foi representado por vários tipos de Processos, dentre os quais os Mentais, por meio dos quais identificou-se a visão do autor e de si mesmo.

Como se pode notar, a LSF tem servido de referencial teórico-metodológico para a análise do texto literário, bem como na pesquisa comparativa de traduções e suas fontes. O presente trabalho se insere, pois, na abordagem discursiva e textual com base na LSF do texto literário e de sua tradução, mais especificamente, dos Processos Mentais da Metafunção Ideacional. A escolha desses processos se justifica devido à sua importância para a compreensão da representação de experiências ficcionais internas ou subjetivas de personagens na ficção literária.

Sendo assim, objetiva-se, neste estudo, demonstrar a importância dos Processos Mentais na representação ideacional do dinamismo subjetivo da narradora, a partir da Metafunção Ideacional. Também constitui objetivo deste artigo, identificar as equivalências e mudanças (shifts) ideacionais na representação de Inés na tradução para o português do Brasil.

A seguir, apresentam-se de modo sucinto aspectos teóricos da LSF, breve contextualização da obra, metodologia utilizada, discussão e análise dos dados sob a ótica da LSF e, finalmente, as considerações finais.

\section{REPRESENTAÇÃO DE EXPERIÊNCIAS INTERNAS}

Os significados experienciais segundo Halliday e Matthiessen $(2004 ; 2014)$ são ativados pelo sistema de transitividade através de recursos linguísticos presentes 
na oração. Sobre o modo como a linguagem opera para produzir representação de experiências humanas, Halliday (1982[1978], p. 33) explica que a:

a linguagem tem que interpretar nossa experiência, reduzindo os fenômenos infinitamente variados do mundo que nos cerca, e também de nosso mundo interno, dos processos de nossa consciência, a um número controlável de classes de fenômenos.

O número controlável de fenômenos que o sistema de transitividade organiza se dá por meio de um Processo a partir do qual podem se identificados: o próprio Processo (verbos); os Participantes (grupos nominais), $\mathrm{e}_{i}$ as Circunstâncias (sintagmas preposicionados e grupos adverbiais).

Para exemplificar, veja-se o excerto do corpus em português:

1 (...) sentimos profunda vergonha.

(a)

(c)

No exemplo (1), a letra (a) indica o evento, o Processo (sentimos) que está ocorrendo, isto é, a experiência interna de Inés e da comunidade da qual faz parte. Já os Participantes dessa experiência interna, Inés e sua comunidade, são os Participantes (nós em elipse) do sentir (sentimos). Por sua vez, (c) é o Fenômeno experienciado (vergonba/segundo Participante). Note-se que (b) (profunda) circunscreve o sentir em um modo específico de sentir.

Sendo o "centro experiencial da oração" (HALLIDAY; MATTHIESSEN, 2004, p. 176), os Processos, junto aos Participantes desses eventos e, eventualmente, às Circunstâncias, constroem (construe) as figuras (figure) experienciais que modelam as experiências humanas (goings-on). Esses Processos são agrupados em seis diferentes tipos pela LSF. Para cada um dos seis Processos haverá pelo menos um Participante obrigatório ou mais. No tocante aos Processos Mentais, foco deste trabalho, são dois os Participantes dos Processos Mentais, o Experienciador (o nós elíptico do exemplo 1) que sente, pensa, deseja ou percebe e o Fenômeno, aquilo que é experienciado (a vergonba do exemplo 1).

Esses Processos, assim como os Verbais, são os únicos que podem projetar outra oração por meio da partícula que ou se, em Projeções do tipo Relato (excerto: "calculei que lutávamos há mais de dez horas"), ou por aspas e travessão, na Citação (eg.: - O adultério é pecado mortal - me lembrou o bispo.).

Resumindo, os Processos Mentais são importantes recursos linguísticos que facilitam o estudo das experiências da consciência e aspectos subjetivos em diversos tipos de textos, em especial no texto literário. Esses recursos resultam de escolhas que evidenciam "crenças, valores e desejos" (SOUZA, 2006, p.461), daí sua 
importância para a descrição mais pormenorizada "dos eventos e dos personagens" (MONTGOMERY, 1993, p. 140) na ficção literária.

Na próxima seção, apresentam-se algumas ideias centrais da LSF na análise do texto literário.

\subsection{A Linguística Sistêmico-Funcional e o texto literário}

A importância da análise do texto literário a partir de suas especificidades e de seu contexto já havia sido discutida por Halliday (2002[1977], p. 46) ao destacar que "para que um texto tenha sentido como literatura deve-se relacioná-lo especificamente a um discurso do universo literário". A ideia central desta afirmativa é que deve-se entender o texto literário como um artefato cultural, como um objeto portador de significados e valores da sociedade onde está inserido (HALLIDAY; MATTHIESSEN, 2004). Em outras palavras:

quando [um texto é] visto como artefato, um leque de possibilidades se nos abre, porque o texto, antes de ser meramente um condensado de estruturas léxico-gramaticais, revela aspectos sociais e culturais que, potencialmente, direcionaram as escolhas linguísticas de seus produtores (RODRIGUES-JÚNIOR, 2015b, p. 410)

Nessa mesma perspectiva, Hasan (1989[1978], p. 20) defende que para entender os significados do texto literário (arte verbal) é necessário buscar a sua "linguagem" e como ela foi usada. Para realizar a análise da arte verbal, a pesquisadora também utiliza o sistema de transitividade e propõe o termo dinamismo para indicar a "capacidade de afetar o mundo à nossa volta" (HASAN, 1978, p.45). A autora explica que o dinamismo estaria localizado no extremo final de um continuum em cujo extremo oposto estaria a passividade, visto que haveria diversos graus de dinamismo.

De modo a ampliar o conceito de dinamismo, propomos o termo dinamismo subjetivo (HOY, 2017) quando associado aos Processos Mentais, abandonando em parte a abordagem relativamente dicotômica (dinamismo X passividade) de Hasan (1978). É Halliday e Matthiessen (2004) que oferecem as pistas para a adoção do termo ao explicar que Processos Materiais, comumente associados a representações de ações por desprenderem certa energia e Processos Mentais relacionados a representações da consciência, por serem mais subjetivos, podem apresentar outras interpretações, pois

Obviamente, orações do fazer [Materiais] e do sentir [Mentais] têm diferentes significados. Mas isto não é suficiente para que constituam categorias gramaticais distintas. Há indefinidas maneiras de traçá-los em bases semânticas, por exemplo, invocando considerações contextuais 'de cima', tal como quando descrevemos estratégias semânticas específicas para um tipo de situação particular (HALLIDAY; MATHHIESSEN, 2004, p.248). 
Quando os autores chamam a atenção para as considerações contextuais estão se referindo à semântica e ao contexto de cultura e de situação que podem interferir na interpretação do texto e classificação dos Processos. Isso reforça a ideia de entender o termo dinamismo subjetivo como o resultado do seu contexto quando este revela a capacidade de afetar o mundo à sua volta como indicado por Hasan (1978). Além do contexto, é possível recorrer aos Processos presentes na oração projetada ou nas expansões (outras orações) quando se referem a um evento capaz de afetar o seu entorno.

Para melhor esclarecimento, vejam-se os exemplos extraídos do corpus em português:

(2) Então me lembrei das empadas e convenci o cozinheiro (...) para que me arranjasse farinha, banha e um pouco de carne-seca, que botei de molho antes de cozinhar.

(3) (...) calculei que lutávamos há mais de dez horas.

No exemplo (2) Inés é a Experienciadora (me) de uma lembrança, o Fenômeno (das empadas). Aparentemente, um Experienciador poderia ser considerado um Participante mais passivo, pois apenas se lembra de algo, mas no exemplo (2) a lembrança de Inés tem resultado prático como se vê pelo contexto da oração. Neste exemplo, outras orações demonstram que Inés se lembrou das empadas e convenceu (Processo Verbal) alguém a ajudá-la a encontrar (Processo Material arranjar) os ingredientes para que ela pudesse cozinbá-las (Processo Material). Como se pode notar, a experiência interna de Inés somente pode ser compreendida como uma ação cujo resultado é a modificação do seu mundo ficcional quando o contexto é levado em conta.

Já o exemplo (3) mostra uma Projeção do Processo (calculei) que apresenta um Processo Material (lutávamos), uma ação que Inés compartilhava com toda a comunidade de Santiago. Nessa representação, Inés é uma Experienciadora de um Processo Mental cognitivo decorrente da participação ativa de Inés na luta contra os indígenas do Chile. O Processo (calculei) é, portanto, uma operação matemática fruto do envolvimento de Inés na luta contra os povos do Chile e poderá ser útil à comunidade para ajudá-los a decidir se vale a pena continuar a lutar.

Isso posto, neste trabalho, o Participante de orações com Processos Mentais poderá ser considerado como portadores de dinamismo subjetivo quando revele a capacidade de afetar a comunidade ficcional da qual fazem parte por meio da descrição e análise contextuais ou do tipo de Processos presentes na Projeção. 
Outra importante contribuição para este trabalho é o conceito de eixo narrativo na análise do ponto de vista (RODRIGUES-JÚNIOR; BARBARA, 2013). Embora esses autores (2013) não o denominem propriamente de eixo narrativo referem-se ao eixo como sendo "o Processo Verbal e o seu diálogo projetado" (p. 266), um recurso linguístico fundamental para a compreensão da "voz narrativa impressa nas projeções de Processos Verbais e no conteúdo da mensagem que constituem o ponto de vista narrativo ou os diálogos realizados pelos personagens" (p. 266).

No presente trabalho, de modo análogo, esse termo será usado nas orações Projetadas por Processos Mentais sendo denominado de eixo do pensamento, de modo a facilitar a análise das experiências internas de personagens de textos literários. Isso quer dizer que todos os aspectos da mente humana estão presentes no eixo do pensamento, isto é, os cognitivos, perceptivos, emotivos e desiderativos, como elencados por Halliday e Matthiessen (2014).

Para compreender melhor o eixo do pensamento, veja-se a exemplificação (4) e sua explicação:

(4) Acho (que estava com o cabelo arrepiado e que cuspia espuma e maldições)

No exemplo (4) Inés (elipse) é a uma Experienciadora do Processo Mental (acho). O conteúdo da oração projetada a partir da partícula (que) desvela a suposição da narradora em relação ao aspecto ameaçador que tivera durante a luta travada contra os indígenas chilenos. A projeção mostra o conteúdo de sua suposição, devido à presença do Processo Relacional (estava) que a classifica como Portadora do Atributo (o cabelo arrepiado) e no Processo Material (cuspia) cujas Metas (espuma e maldições) contribuem para a representação de Inés como uma pessoa ameaçadora, segundo seu próprio ponto de vista.

Depreende-se disso, que o eixodopensamento poderá trazervaliosas contribuições para o entendimento do ponto de vista da narradora em Inés del alma mía e em sua tradução.

A seguir, será apresentada uma breve explanação sobre alguns conceitos úteis para este trabalho, desenvolvidos pela LSF em Estudos da Tradução.

\subsection{A Linguística Sistêmico-Funcional e o texto literário traduzido}

Inúmeros têm sido os Estudos da Tradução na interface da LSF a partir de uma abordagem textual ou discursiva com o objetivo de realizar análises comparativas da linguagem em contextos de cultura e de situação e de sistemas linguísticos diferentes (texto fonte e texto traduzido). O surgimento destes trabalhos remonta às décadas 
de 1970 e 1980, época que ficou marcada por grandes mudanças nos Estudos da Tradução, possibilitando a ampliação do "escopo" da disciplina (BAKER; PÉREZGONZALES, 2013, p. 41).

Embora não possa ser incluído nas abordagens discursivas da tradução, o trabalho de Catford (1965) destaca-se por ter sido o primeiro a trabalhar na interface da LSF e dos Estudos da Tradução. Em seu trabalho ele fez a distinção entre a equivalência textual e a correspondência formal, a partir das quais introduziu o conceito de mudanças (shifts) quando não se verifica a correspondência formal entre as unidades linguísticas de um texto fonte (TF) e o texto alvo (TA) durante a tradução. Essas mudanças são definidas por Catford (1965, p. 73) como "desvios na correspondência formal no processo de passar do TF [texto fonte] para o TA [texto alvo]".

É sabido que, posteriormente, o trabalho de Catford sofreu várias críticas. Não obstante, não se pode negar que seu trabalho apresenta enormes contribuições para os estudos sistêmicos funcionais da tradução, sobretudo pelo seu pioneirismo. Até mesmo pesquisadores como Matthiessen (2001) argumentam que Catford:

[apresenta] uma teoria linguística da tradução que é uma ótima contribuição; ele desenvolveu um quadro bastante abrangente da tradução através de um sistemático exame de uma esclarecedora teoria da linguagem que pode servir como base para esforços similares na atualidade. A tarefa teórica central é expandir a sua proposta sob a luz dos novos desenvolvimentos teóricos e descobertas descritivas.

Em relação à expansão dos estudos de Catford, o próprio Matthiessen é um representante dos teóricos que pretendem ampliar os estudos da tradução em LSF, como propõe na citação acima. Com esse objetivo, o autor discute os conceitos de equivalência e mudança sob uma nova perspectiva. Para Matthiessen (2001, p. 51) as mudanças podem ocorrer no interior das Metafunções (Ideacional, Interpessoal ou Textual), uma vez que o processo tradutório "está localizado muito mais no nível semântico do que no léxico gramático (ou o nível da expressão); e, além disso, está localizado em um contexto (de cultura) aproximado como o original".

Com base em Catford (1965), Rodrigues-Júnior e Garcia de Oliveira (2015a) ampliaram o conceito de mudança denominando-o de mudança ideacional. Contudo, diferentemente de Catford (1965), essa mudança não estaria relacionada somente às mudanças "classe-gramatical", mas às "mudanças (shifts) ideacionais" (p. 399). Nessa perspectiva, para identificar as mudanças ideacionais em um texto traduzido é necessário observar os elementos da transitividade: os "processos, participantes, circunstâncias e expansões" (RODRIGUES-JÚNIOR; GARCIA de OLIVEIRA, 2015a, p. 399), e até mesmo as projeções do eixo do pensamento. Por analogia, a 
equivalência também pode ser abordada na Metafunção Ideacional, adotando-se o termo equivalência ideacional.

Devido à importância dos conceitos de equivalência ideacional e mudança ideacional entre Texto Fonte (TF) e Texto Alvo (TA), estes serão utilizados como categorias analíticas na representação de Inés como Experienciadora.

Na próxima seção, será apresentada uma sucinta contextualização da obra.

\section{CONTEXTUALIZAÇÃO DE INÉS DEL ALMA MÍA}

Levando-se em conta o papel central que os contextos de cultura (mais amplo) e de situação (mais imediato e próximo da comunicação) têm na escolha dos recursos linguísticos feita pelos usuários da língua, convém apresentar uma breve contextualização da obra.

Inés del alma mía foi escrito por Isabel Allende, destacada escritora chilena, cuja produção literária tem sido traduzida para os mais diversos idiomas, como informado em seu site pessoal ${ }^{1}$. Segundo Lopes (2012, p. 101) destaca-se dessa produção, "La casa de los siete espejos (1975), La Casa de los Espíritus (1982), Cuentos de Eva Luna (1987), Inés del alma mía (2006)", dentre outros.

Foi em La casa de los Espíritus que o "feminismo" da escritora ficou evidente, revelando "uma progressiva emancipação da mulher" em sua narrativa (NAVARRO, 1995, p.16). Também, foi com esse romance que a escritora conquistou avaliações positivas de diversos especialistas em literatura, o que não lhe garantiu imunidade a críticas severas ao longo de sua carreira como escritora.

O papel significativo de Isabel Allende para a literatura latino americana foi notado por Navarro (1995) ao indicar que ela deu voz e um papel destacado às mulheres em muitas de suas obras. De fato, muitas dessas mulheres foram as narradoras e protagonistas dos contos e romances da escritora, cujas características principais é a de terem sido "mulheres fortes, decididas a enfrentar e superar qualquer obstáculo, paixões incontroláveis, justiça, senso de honra, amizade, dor, morte, violência" (CANELLO, 2008, pp. 23-24).

Inés del alma mia é um romance histórico narrado em uma perspectiva autobiográfica em primeira pessoa por Inés Suarez, importante figura histórica que participou ativamente da conquista do Chile e da fundação de Santiago. Essa narrativa inclui a vida da narradora e personagem principal Inés, bem como o choque entre culturas diferentes (entre os espanhóis e indígenas chilenos), as lutas travadas

1. In: $<$ http://www.isabelallende.com $>$. 
entre eles, a crueldade presente nessas relações, e ainda as relações de amizade e de amor nas terras há pouco conquistadas.

A narradora possui vários tipos de conhecimentos que a distinguem do papel que a história tem dado às mulheres ao longo dos tempos, dado que "desde o inicio dos tempos, o saber é proibido às mulheres (...). O saber, que é sagrado, é uma exclusividade de Deus e do homem, seu representante na Terra" (PERROT, 2009, p. 77). Ela também não se enquadra no tipo de mulher da sociedade chilena do século XVI, quer dizer, no padrão da "boa mulher" recatada, humilde, obediente e casta (ARISMENDI, 2006).

Da documentação histórica, o nome de Inés Suarez é registrado nas Crônicas do Reino de Chile (LOVERA, 1865), uma das bibliografias consultadas por Isabel Allende. Nessas Crônicas, encontra-se a descrição da cena em que Inés Suarez, diante da indecisão dos soldados, ela própria mata com golpes de espada os sete caciques que eram prisioneiros de Pedro de Valdívia². Por sua vez, o historiador Diego de Barros Arana (2000, p. 173), também citado com fonte histórica por Isabel Allende, destaca que ela estava "destinada a conquistar um célebre nome nas primeiras páginas da história".

É certo que Inés faz parte da história do Chile durante o processo de conquista, constando em registros de cronistas e historiadores. Apesar disso, não raro, ela tem sido esquecida pela história oficial, como demonstrado por Maciel (2007) ou Canello (2008), daí a importância da ficção literária em que ela pode ser representada de novas maneiras.

A seguir, serão apresentados os procedimentos metodológicos.

\section{METODOLOGIA}

O presente estudo de caso contou com uma abordagem quali quantitativa cuja orientação metodológica é da Linguística de Corpus, empregada por favorecer a "exploração da linguagem através de evidências empíricas, extraídas por computador" (BERBER SARDINHA, 2000, p.2). Utilizou-se o programa computacional WordSmith Tools (6.0) por meio do qual organizaram-se quantitativamente os dados para análise, facilitando, por exemplo, a identificação de padrões linguísticos, frequência, análise comparativa entre TF e TA.

2. Pedro de Valdívia, amante de Inés Suarez, foi o responsável pela conquista do Chile durante o século XVI. 
Feita a digitalização dos textos em formato txt, única forma que o programa pode realizar a leitura, os textos foram submetidos a três ferramentas do Word Smith Tools. Primeiramente, extraíram-se as palavras mais frequentes da lista de palavras (word list), de modo a identificar os tipos de Processos Mentais vinculados à narradora e sua frequência, verificando-se que há uma pequena diferença entre a totalidade de processos no TF (1951) e a no TA (1869). Essa diferença entre os textos apontava para uma possível presença de mudanças ideacionais nos corpora, que foi verificada com o concordanciador (concord) e confirmada pelo alinhador (Viewer and Aligner) ao disponibilizar as linhas de concordância do TF e do TA lado a lado.

Confirmada a presença de equivalências e mudanças ideacionais, as ocorrências foram contabilizadas e organizadas em uma tabela de modo a visualizar melhor os dados. Feito isso, a análise da transitividade foi realizada com base na LSF de Halliday e Matthiessen $(2004 ;$ 2014) e trabalhos de descrição da língua portuguesa (FUZER ; CABRAL, 2010; 2014) e espanhola em LSF (GHIO; FERNÁNDEZ, 2008). Na descrição da representação de Inés no papel de Experienciadora, observam-se os elementos de transitividade, a saber: Processos Mentais + Experienciadora + Circunstância. A partir desses elementos, identifica-se o dinamismo subjetivo com base no contexto e no eixo do pensamento.

$\mathrm{Na}$ análise da Equivalência observa-se se os elementos da transitividade foram utilizados de modo equivalente, não ocorrendo, será considerado que houve mudança ideacional quando um dos elementos da transitividade não for equivalente ou quando houve mudança no eixo do pensamento ou nas expansões.

Para melhor compreensão da mudança ideacional, segue o exemplo 5:

5. No be olvidado

Experienciadora (elipse) + P. Mental

Não esqueci

Experienciadora (elipse) + P. Mental nuestro primer abrazo

(a) Fenômeno

a primeira vez que fizemos amor

(b) Fenômeno

No exemplo (5) embora Inés seja uma Experienciadora de uma lembrança (he olvidado/esqueci), pode-se, contudo, identificar uma mudança ideacional no Fenômeno (b) experienciado por Inés (elipse) no texto traduzido. O Fenômeno (b) é uma experiência ficcional interna de Inés que representa o seu primeiro encontro sexual, destacando-se a sexualidade da narradora. De modo distinto, a representação do Fenômeno (a) no texto fonte representa o abraço dado pela primeira vez, prevalecendo uma visão mais romântica da narradora.

$\mathrm{Na}$ próxima seção, seguem a discussão e análise dos dados. 


\section{DISCUSSÃO E ANÁLISE DOS DADOS}

Os dados mostraram que a representação de Inés foi bem variada, sendo utilizados muitos Processos Mentais. Foram verificados quatro tipos de Processos mentais: i) cognitivos (eg. saber/saber; creer/crer; conocer/conbecer; calcular/calcular); ii) desiderativos (eg. desear/desejar, esperar/esperar, querer/querer); iii) emotivos (eg. sentir/sentir, gustar/gostar, amar/amar); iv) perceptivos (eg. ver/ver, notar/notar, observar/observar).

Para melhor visualização, o número variado de Processos foi organizado na tabela 1: 
Tabela 1. Total de Processos mentais no TF e no TA

\begin{tabular}{|c|c|c|}
\hline \multicolumn{3}{|c|}{ Total de processos mentais } \\
\hline Processos & es & $\mathrm{pt}$ \\
\hline Ver/ver & 250 & 242 \\
\hline Saber/saber & 194 & 203 \\
\hline Querer/querer & 105 & 113 \\
\hline Creer/crer & 94 & 2 \\
\hline Pensar/pensar & 84 & 109 \\
\hline Sentir/sentir & 80 & 81 \\
\hline Conocer/conhecer & 88 & 91 \\
\hline Desear/desejar & 78 & 82 \\
\hline Esperar/esperar & 77 & 82 \\
\hline Suponer/supor & 62 & 44 \\
\hline Recordar/recordar & 56 & 3 \\
\hline Decidir/decidir & 52 & 52 \\
\hline Amar/amar & 40 & 44 \\
\hline Comprender/compreender & 46 & 46 \\
\hline Temer/temer & 49 & 44 \\
\hline Imaginar/imaginar & 42 & 44 \\
\hline Aprender/aprender & 35 & 35 \\
\hline Pretender/pretender & 34 & 33 \\
\hline Olvidar/esquecer & 34 & 34 \\
\hline Acordar/lembrar & 34 & 65 \\
\hline Necesitar/necessitar & 33 & 26 \\
\hline Descubrir/descobrir & 33 & 38 \\
\hline Preferir/preferir & 31 & 29 \\
\hline Entender/entender & 28 & 33 \\
\hline Gustar/gostar & 24 & 28 \\
\hline Calcular/calcular & 22 & 21 \\
\hline Aceptar/aceitar & 20 & 21 \\
\hline Observar/observar & 20 & 22 \\
\hline Sospechar/suspeitar & 20 & 21 \\
\hline Merecer/merecer & 19 & 19 \\
\hline Comprobar/comprovar & 18 & 20 \\
\hline Adivinar/adivinhar & 18 & 15 \\
\hline Interesar/interessar & 17 & 17 \\
\hline Enterar/inteirar & 16 & 12 \\
\hline Considerar/considerar & 16 & 16 \\
\hline Dudar/duvidar & 15 & 12 \\
\hline Convenir/convir & 14 & 14 \\
\hline Importar/importar & 12 & 12 \\
\hline Notar/notar & 10 & 13 \\
\hline Lamentar/lamentar & 10 & 9 \\
\hline Ignorar/ignorar & 8 & 9 \\
\hline Concluir/concluir & 7 & 7 \\
\hline Detestar/detestar & 6 & 6 \\
\hline TOTAL & 1951 & 1869 \\
\hline
\end{tabular}

Fonte: própria 
A tabela 1 mostra que a representação de Inés contou com 43 formas verbais utilizadas, recursos linguísticos que contribuem para uma variada representação de experiências internas de Inés. Os dados apontam para um nível elevado de equivalência ideacional entre os textos, com exceção de alguns Processos que parecem indicar mudanças ideacionais, tais como creer/crer (94/2), pensar/pensar (84/109), suponer/supor (62/44), recordar/recordar (56/3), acordar/lembrar (34/65).

Porém, uma análise mais detalhada revelou que nesse grupo de Processos foram utilizados outros equivalentes tradutórios, embora também tenham sido encontradas mudanças Ideacionais como será mostrado mais adiante. Um exemplo de equivalência tradutória ocorreu com o Processo creer no TF que foi retextualizado no TA por quatro equivalentes tradutórios, (achar, acreditar, pensar e crer), talvez por serem verbos mais usuais no português brasileiro. De modo a compreender melhor o nível de equivalências e mudanças Ideacionais, foi elaborada a tabela 2 que conta com a realização dos Processos Mentais no TF e TA: 
Tabela 2. Realização dos Processos Mentais no TF e TA

\begin{tabular}{|c|c|c|c|c|c|c|c|c|}
\hline \multicolumn{6}{|c|}{ Uso dos processos mentais na representação de Inés } & \multirow{2}{*}{\multicolumn{3}{|c|}{$\begin{array}{c}\text { Outros usos } \\
\text { Outro tipo de processo ou } \\
\text { omissão no TA }\end{array}$}} \\
\hline \multirow{2}{*}{$\begin{array}{l}\text { Processos Mentais } \\
\text { usados na } \\
\text { Representação de } \\
\text { Inés no TF }\end{array}$} & \multicolumn{2}{|c|}{$\begin{array}{l}\text { Realizado pelo } \\
\text { mesmo processo no } \\
\text { TA }\end{array}$} & \multicolumn{3}{|c|}{$\begin{array}{c}\text { Realizado por outro } \\
\text { processo Mental no TA }\end{array}$} & & & \\
\hline & N. ${ }^{\circ}$ & $\%$ & Processo & N. ${ }^{\circ}$ & $\%$ & Processo & N. ${ }^{\circ}$ & $\%$ \\
\hline Saber (82) & 80 & $97 \%$ & Ver & $\overline{1}$ & $2 \%$ & Omissão & $\overline{1}$ & $1 \%$ \\
\hline & & & Achar & 30 & $68 \%$ & & & \\
\hline & & & Acreditar & 9 & $20 \%$ & & & \\
\hline Creer (44) & 1 & $3 \%$ & Pensar & 4 & $9 \%$ & & & \\
\hline Ver (40) & 39 & $98 \%$ & Observar & 1 & $2 \%$ & & & \\
\hline Pensar (40) & 40 & $100 \%$ & & & & & & \\
\hline Recordar (31) & - & - & Lembrar & 31 & $100 \%$ & & & \\
\hline Suponer (30) & 30 & $100 \%$ & & & & & & \\
\hline Sentir (25) & 25 & $100 \%$ & & & & & & \\
\hline Querer (22) & 19 & $86 \%$ & Gostar & 3 & $14 \%$ & & & \\
\hline Desear (20) & 20 & $100 \%$ & & & & & & \\
\hline Imaginar (18) & 18 & $100 \%$ & & & & & & \\
\hline Olvidar (18) & 18 & $100 \%$ & & & & & & \\
\hline $\operatorname{Amar}(18)$ & 18 & $100 \%$ & & & & & & \\
\hline Comprender (17) & 17 & $17 \%$ & & & & & & \\
\hline Temer (17) & 16 & $94 \%$ & & & & Ter & 1 & $6 \%$ \\
\hline Conocer (15) & 15 & $100 \%$ & & & & & & \\
\hline Decidir (14) & 13 & $93 \%$ & Pensar & 1 & $7 \%$ & & & \\
\hline Comprobar (14) & 14 & $100 \%$ & & & & & & \\
\hline Aprender (12) & 12 & $100 \%$ & & & & & & \\
\hline Preferir (12) & 12 & $100 \%$ & & & & & & \\
\hline Sospechar (11) & 11 & $100 \%$ & & & & & & \\
\hline Gustar (11) & 11 & $100 \%$ & & & & & & \\
\hline Pretender (9) & 9 & $100 \%$ & & & & & & \\
\hline Enterar (8) & 5 & $63 \%$ & Saber & 3 & $37 \%$ & & & \\
\hline Observar (8) & 8 & $100 \%$ & & & & & & \\
\hline Entender (7) & 7 & $100 \%$ & & & & & & \\
\hline Descubrir (7) & 7 & $100 \%$ & & & & & & \\
\hline Necesitar (6) & 5 & $83 \%$ & Precisar & 1 & $17 \%$ & & & \\
\hline Acordar (5) & 5 & $100 \%$ & & & & & & \\
\hline Calcular (5) & 5 & $100 \%$ & & & & & & \\
\hline Adivinar (5) & 4 & $100 \%$ & & & & & & \\
\hline Dudar (4) & 4 & $100 \%$ & & & & & & \\
\hline Esperar (4) & 4 & $100 \%$ & & & & & & \\
\hline Concluir (4) & 4 & $100 \%$ & & & & & & \\
\hline Lamentar (4) & 4 & $100 \%$ & & & & & & \\
\hline Considerar (3) & 3 & $100 \%$ & & & & & & \\
\hline Interesar (3) & 3 & $100 \%$ & & & & & & \\
\hline Aceptar (3) & 3 & $100 \%$ & & & & & & \\
\hline Convenir (3) & 3 & $100 \%$ & & & & & & \\
\hline Notar (3) & 3 & $100 \%$ & & & & & & \\
\hline Ignorar (3) & 3 & $100 \%$ & & & & & & \\
\hline Detestar (2) & 2 & $100 \%$ & & & & & & \\
\hline Merecer (2) & 2 & $100 \%$ & & & & & & \\
\hline Importar (1) & 1 & $100 \%$ & & & & & & \\
\hline
\end{tabular}

Fonte: Própria 
É perceptível que a tabela (2) mostra um número elevado de equivalências tradutórias nas escolhas linguísticas do TA. Além disso, vários Processos Mentais contaram com equivalentes tradutórios como o já citado creer/ achar, acreditar, pensar e crer, bem como os Processos saber/saber, ver; ver/ver, observar; recordar/lembrar; querer/ querer, gostar; decidir/decidir, pensar; enterar/saber; necesitar/precisar.

Em relação às mudanças ideacionais verificadas na tabela (2), o número é bem reduzido, ocorrendo em somente dois Processos: em saber, omitido uma vez no TA, e: em temer, retextualizado no TA como ter. É bom lembrar que a tabela (2) apenas mostra a mudança ocorrida no Processo, sendo necessário verificar os outros elementos da transitividade (Participantes, Circunstância), as expansões e o eixo do pensamento para identificar possíveis mudanças Ideacionais.

A tabela (2) também revela o uso de um número considerável de Processos Mentais que constroem uma representação de Inés como Experienciadora de variadas experiências internas, as quais foram agrupadas em seis temáticas:

Figura 2. Temáticas das representações de Inés

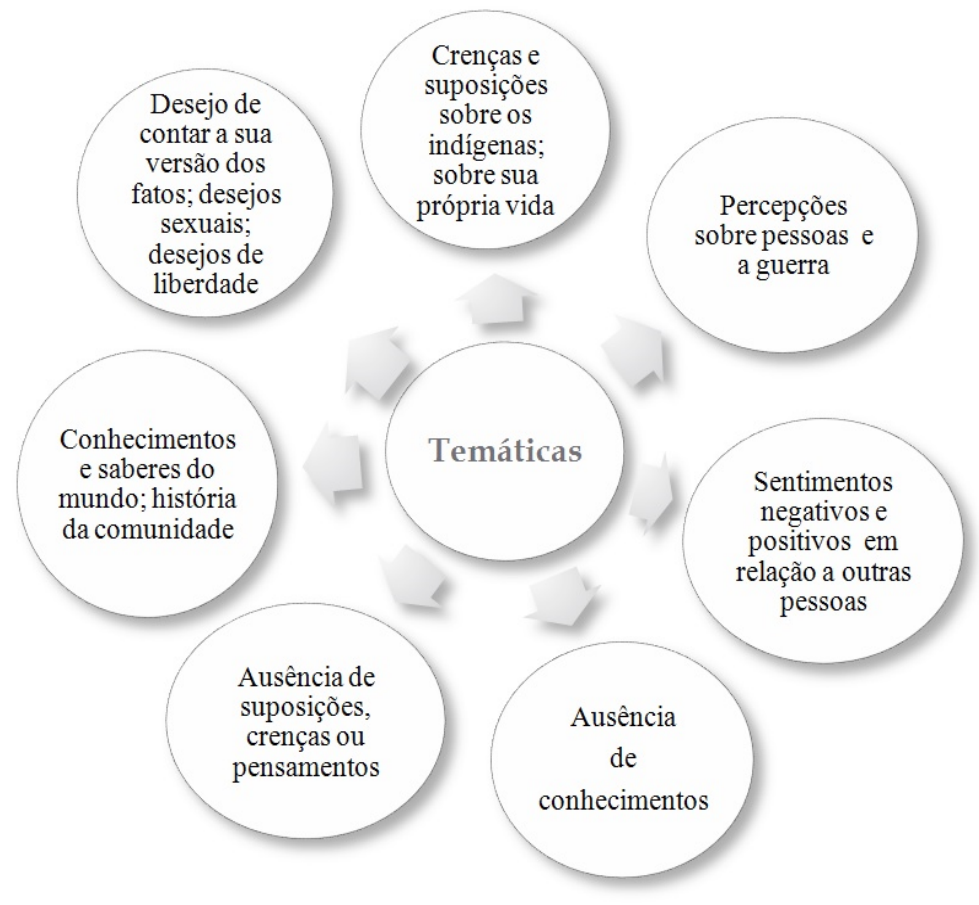

Fonte: Própria 
Das temáticas, identificaram-se experiências ficcionais da consciência de Inés relacionadas: às percepções de objetos, pessoas à sua volta, de si mesma e de eventos sobrenaturais; conhecimentos sobre outros personagens e atividades em geral; de emoções negativas e positivas acerca de outros personagens; desejos variados; pensamentos sobre o mundo e outros personagens.

Foram inúmeros os Fenômenos como descrito por Halliday e Matthiessen (2014), sendo realizados na gramática por Substantivos, sobretudo, pessoas (Pensé em Rodrigo, y la necesidad de hacer el amor con él me hizo estremecer / Pensei em Rodrigo, e a necessidade de fazer amor com ele me fez estremecer; abstrações (Vi a la Muerte, un poco borrosa / Vi a Morte, um pouco apagada; objetos (Disponíamos de muy pocos libros y los [lós libros] conocíamos de memória / Dispúnhamos de muito poucos livros e os [os livros] conhecíamos de memória); lugares (vimos varias aldeas, muchos plantíos, canales de riego, acequias y caminos./ vimos várias aldeias, muitas plantações, canais de irrigação e caminhos ).

Com base nas temáticas da figura (2), na próxima seção, foram selecionados alguns exemplos para mostrar, primeiramente, a análise das equivalências ideacionais e, em segundo, algumas ocorrências de mudanças ideacionais. Além disso, associado a estes aspectos, também será abordada a presença de dinamismo subjetivo na representação de Inés como Experienciadora.

\subsection{Equivalência ideacional e dinamismo subjetivo na representação de Inés}

O uso dos Processos Mentais no TF e no TA apresenta um nível elevado de Equivalências como se pode atestar na tabela (2). As experiências internas de Inés estão relacionadas à cognição, emoção, desejos e percepções, como se pode ver nos exemplos a seguir.

10. me gané la vida con los oficios que conozco: coser, cocinar, componer huesos y curar heridas.

ganhei a vida com os ofícios que conbeço: costurar, cozinhar, consertar ossos e curar feridas.

No exemplo (10), a equivalência ideacional manteve-se e Inés foi representada como uma Experienciadora do Fenômeno (ofícios) cujo eixo narrativo é composto de Processos Materiais (costurar, cozinhar, consertar, curar) que representam várias ações praticadas por Inés. Na representação de Inés como Experiêncidora, claramente, se 
percebe o dinamismo subjetivo da narradora, porque o conhecimento resultou de uma série de ações realizadas anteriormente.

Sabe-se pelas informações contextuais que Inés beneficiava a sua comunidade com as ações de costurar, cozinhar, concertar ossos e curar feridas, daí o dinamismo subjetivo ser evidenciado pelo processo Processo Mental conheço.

11. A mí me tocó reponer la salud de los heridos y enfermos y hacer lo que más me gusta: fundar.

Para mim tocou repor a saúde dos feridos e doentes e fazer o que mais gosto: construir.

Observa-se que no exemplo (11) do TF, as experiências internas de Inés são vinculadas a um Processo Mental emotivo (gusta/gosto), que a princípio poderia dar a impressão de que sua representação é menos dinâmica. Entretanto, a análise do eixo do pensamento, isto é, da Projeção de Ideia composta pelo Processo Material (fundar/construir) revela que há dinamismo subjetivo nessa representação. Nesse eixo do pensamento, a experiência interna de Inés é associada ao ato de fundar/ construir, uma ação material que afeta positivamente a comunidade, uma vez que, pelo contexto, sabe-se que se trata da construção de cidades, hospitais, igrejas, dentre outros.

Nesse mesmo exemplo (11), observou-se que, no TA, embora tenha ocorrido uma mudança (shift) intra-sistema na Projeção de Ideia (no sistema de tipos de Processos: fundar/construir), manteve-se a equivalência ideacional, pois o sentido de fundar é o mesmo de construir.

12. lo observaba, tan espantada como el pero dispuesta a saltarle encima si gritaba $(. .$.

observava-o, tão espantada quanto ele, mas disposta a lhe saltar em cima se gritasse $(\ldots)$

A oração do exemplo (12) contém uma mudança de estrutura no TA que inverte a oração do TF (lo observaba) por (observa-o), não provocando, porém, uma mudança ideacional na representação de Inés como Experienciadora. Essa representação, não é apenas a experiência de alguém que observa de modo contemplativo, mas de alguém que tenta identificar as intenções de seu agressor para tomar uma atitude, denotando o dinamismo subjetivo da narradora. 


\subsection{Mudanças ideacionais e dinamismo subjetivo na representação de Inés}

A análise dos dados mostra que as escolhas tradutórias não provocaram um número significativo de Mudanças Ideacionais. Todavia, essas Mudanças Ideacionais são relevantes para um corpus de pequeno porte dado que elas podem contribuir substancialmente na representação das experiências internas da narradora, e, consequentemente na imagem dessa narradora.

Para ter-se uma ideia das Mudanças Ideacionais identificadas, estas foram organizadas na tabela 3 :

Tabela 3. Mudanças Ideacionais

\begin{tabular}{|c|c|c|c|c|c|c|c|}
\hline $\begin{array}{c}\text { Representação de Inés co } \\
\text { Experienciadora }\end{array}$ & & $\begin{array}{c}\text { Mudança do } \\
\text { Processo/ } \\
\text { Participante } \\
\text { no TA }\end{array}$ & $\begin{array}{c}\text { Mudança da } \\
\text { Circunstância } \\
\text { no TA }\end{array}$ & $\begin{array}{c}\text { Mudança no } \\
\text { conteúdo da } \\
\text { Projeção no } \\
\text { TA }\end{array}$ & $\begin{array}{c}\text { Mudança por } \\
\text { omissão da } \\
\text { linha de } \\
\text { concordância } \\
\text { ou do Processo } \\
\text { no TA } \\
\end{array}$ & $\begin{array}{c}\text { Mudança do } \\
\text { Fenômeno } \\
\text { no TA } \\
\end{array}$ & $\begin{array}{c}\text { Total de } \\
\text { Mudanças } \\
\text { Ideacionais } \\
\text { de Inés no } \\
\text { TA }\end{array}$ \\
\hline Processos no TF & es & $\mathbf{N}^{\circ}$ & $\mathbf{N}^{\circ}$ & $\mathbf{N}^{\circ}$ & $\mathbf{N}^{\circ}$ & $\mathbf{N}^{\circ}$ & $\mathrm{N}^{\circ}$ \\
\hline Saber & 82 & 1 & - & 1 & 1 & 1 & 4 \\
\hline Creer & 44 & - & 1 & 2 & - & 3 & \\
\hline Ver & 40 & - & - & 1 & - & & \\
\hline Pensar & 40 & - & - & - & - & 3 & \\
\hline Suponer & 30 & - & - & 2 & - & - & \\
\hline Sentir & 25 & - & - & - & - & 1 & \\
\hline Querer & 22 & - & 2 & - & - & - & \\
\hline Imaginar & 18 & - & - & - & - & 1 & \\
\hline Olvidar & 18 & - & - & - & - & 2 & \\
\hline Temer & 17 & 1 & - & - & - & - & \\
\hline Necesitar & 6 & - & - & - & - & 1 & \\
\hline Esperar & 4 & & 1 & - & - & - & \\
\hline Dudar & 4 & 1 & & - & - & - & \\
\hline TOTAL & 350 & 3 & 4 & 6 & 1 & 12 & 26 \\
\hline
\end{tabular}

Fonte: Própria

Os dados da tabela (3) mostram que dos 43 Processos Mentais, 13 sofreram mudanças Ideacionais, o que corresponde a $30 \%$ dos 43 Processos. Verifica-se que o Fenômeno foi o elemento que mais sofreu as mudanças Ideacionais (12 ocorrências), seguido das mudanças ocorridas no conteúdo da Projeção, ou seja, no eixo do pensamento (6 ocorrências). Logo depois, seguem as mudanças Ideacionais na Circunstância (com 4 ocorrências), as mudanças no Participante (3 ocorrências), e, finalmente, as mudanças por omissão que conta com 1 ocorrência, conforme dados da tabela (3).

É necessário alertar que, apesar de o Fenômeno ter sido o elemento que mais sofreu mudanças, uma das prováveis causas pode ser atribuída às diferenças entre 
o sistema linguístico do TF e do TA. Por exemplo, na língua espanhola é comum o uso do pronome átono (lo) como objeto direto (Sin pensarlo, me levanté las sayas y lo coloqué en ellas...), algo dispensável no português do Brasil (Sem pensar, levantei as saias e o coloquei nelas...).

Para melhor compreender as mudanças Ideacionais, seguem algumas exemplificações com suas respectivas análises.

13. No podría jurarlo, pero creo que hubo una leve sonrisa en su rostro color de tierra [de Michimalonko, chefe indígena].

Não poderia jurar, mas acho que vislumbrei um leve sorriso em seu rosto cor-de-terra [de Michimalonko, chefe indígena].

No TF do exemplo (13) é o conteúdo da experiência subjetiva de Inés que se modifica com as escolhas linguísticas do tradutor. Ela continua a ser a Experienciadora de uma suposição (creo/acho), detalhada na oração Projetada que constitui o eixo do pensamento da narradora. A mudança é verificada justamente na oração iniciada com o relativo (que) devido à presença de um Processo Existencial (bubo) e um Existente (una leve sonrisa en su rostro color de tierra).

No TA Inés também é representada como Experienciadora do Processo Mental (acho), verificando-se, portanto, uma mudança ideacional não no Processo, mas no conteúdo da experiência interna de Inés. No TF a suposição da narradora refere-se à existência de um aspecto do rosto de Michimalonko, já no TA trata-se de uma percepção (vislumbrei) de Inés em relação ao leve sorriso de Michimalonko. A representação de Inés como Experienciadora de uma percepção põe em relevo a capacidade de Inés traçar uma imagem mental de Michimalonco a partir de uma atividade mental que ela realiza de perceber certos traços no rosto do chefe indígena.

14. No es divertido ir a dar a una mazmorra de la Inquisición; por menos de lo que nosotras [Inés e Catalina] sabíamos, muchos desventurados han terminado en la hoguera.

Não era divertido ir parar numa masmorra da Inquisição; por muito menos que isso [omissão do Processo sabíamos], muitos infelizes terminaram na fogueira.

No exemplo (14) do TF, Inés e Catalina são representadas como Experienciadoras de um saber (sabíamos). Isto quer dizer que elas dominam o 
conhecimento sobre a Inquisição e dos atos que podem ser considerados crimes para o tribunal do Santo Ofício ${ }^{3}$ e os castigos que os hereges receberiam.

No TA foi suprimido o Processo Mental (sabíamos) e, por conseguinte, as Experienciadoras Inés e Catalina, ocorrendo, portanto, uma mudança ideacional. Com essa omissão, há um apagamento da representação ideacional da experiência interna de Inés e de sua amiga no TA, representando-se apenas o fato de que várias pessoas terminaram na fogueira.

15. Buscad otra lavandera, porque no os quiero en mi casa.

Arrume outra lavadeira, porque não o quero mais em minha casa.

No TF do exemplo (15), a representação de Inés como Experienciadora (elipse) de um desejo (quiero) resultou de uma ordem dada por Inés no papel de Ator do Processo Material (buscad). A polaridade negativa (no) junto ao Processo Mental desiderativo (quiero) a situa no âmbito de um desejo negativo em relação ao alferes Núñez, o Fenômeno experienciado (os) por Inés, a quem ela ordena que busque outra lavadeira devido à suas muitas investidas. A Circunstância de local (em mi casa) desempenha o papel importante na representação ideacional de Inés por indicar o local onde o alferes não é desejado por ela.

A análise do TA, revela a mesma representação ideacional de Inés em relação a seu papel de Experienciadora (elipse) de um desejo (quero), cujo Fenômeno (o) também é mantido, assim como a Circunstância de local (em minha casa). Todavia, o acréscimo da Circunstância de intensidade (mais) acrescenta maior energia à experiência subjetiva de Inés em não desejar a permanência do alferes Núñez em sua casa. Em outras palavras, com esse acréscimo, ocorre uma mudança ideacional na representação da experiência interna de Inés, produzindo-se um maior destaque no desejo de Inés.

\section{CONSIDERAÇÕES FINAIS}

$\mathrm{Na}$ representação ideacional de Inés como Experienciadora exploram-se experiências subjetivas de conhecimentos, pensamentos, sentimentos e percepções, muitas delas resultado de ações que afetam a sua comunidade, demonstrando-se

3. A Inquisição, também chamada de Tribunal do Santo Ofício, era uma instituição eclesiástica com o poder de julgar casos pretensos hereges, feiticeiros, bruxas, mas na verdade, buscava condenar muçulmanos, gays, judeus ou quem tivesse ideias condenadas pela Igreja Católica. Os suspeitos ou culpados sofreriam os mais variados castigos, como torturas físicas ou psicológicas e, até mesmo, a morte na fogueira. 
com isso, o dinamismo subjetivo da narradora. Nesse sentido, a representação de Inés como Experienciadora desvela a imagem de uma mulher que: i) pensa a respeito do mundo, da sociedade e de outros personagens; ii) reflete sobre a sociedade da qual faz parte; iii) é dona de conhecimentos que resultaram de suas próprias ações e é capaz de compartilha-los com sua comunidade; iv) assume seus sentimentos e desejos.

Com essas representações, altera-se a visão patriarcal da mulher, sobretudo, em relação à representação de saberes e conhecimentos que Inés possui, uma vez que ao longo da história da humanidade "o mundo das ideias [era reservado] aos homens" (TONI, 2011, p. 22). Em outras palavras, o uso de Processos Mentais contribuiu para a representação do dinamismo subjetivo de Inés.

Nas Projeções que compõem o eixo pensamento, a totalidade das ocorrências foi o Relato, forma prototípica de orações com Processos Mentais segundo Halliday e Mathiessen (2014). Essa escolha reforça o ponto de vista que narradora tem de suas próprias experiências, dando a conhecer mais sobre o que pensa, sabe, sente, e acha. Além disso, vale mencionar, que os elementos de transitividade do eixo do pensamento não se restringem a representações de reflexões de Inés, como tem apontado os estudos literários, mas também a representações de suas emoções, conhecimentos, percepções, contribuindo para uma descrição mais ampla da subjetividade de Inés.

Em relação à comparação da representação de Inés como Experienciadora no TF com o TA, nota-se a preferência pela equivalência ideacional nas escolhas tradutórias, embora também tenham sido identificadas algumas escolhas que provocaram mudanças ideacionais. Cabe lembrar que a maior parte das mudanças não ocorreu nos Processos, mas em outros elementos da transitividade (Circunstâncias, Fenômenos), nas Projeções (eixo do pensamento), nas expansões ou por omissão.

Uma das possíveis explicações para a considerável presença de equivalências ideacionais pode ser encontrada na semelhança entre as duas línguas românicas que favoreceu a escolha de escolhas lexicais idênticas ou de outros equivalentes tradutórios, embora seja inegável que as mudanças aqui descritas também refletem possíveis adaptações necessárias para a língua-alvo da tradução (cf. HALLIDAY, 2001; YALLOP, 2001; RODRIGUES-JÚNIOR, 2010; LIMA-LOPES, 2018) Além dessa explicação, acredita-se que a expertise do tradutor possa ter contribuído para escolhas no nível da equivalência ideacional, a julgar pelas várias obras traduzidas da língua espanhola para o português pelo tradutor.

Em relação às mudanças ideacionais, há várias hipóteses para explicar as escolhas linguísticas do tradutor, como por exemplo, a influência da língua do TF 
no TA, a adoção de padrões linguísticos da língua alvo diferentes da língua fonte, gosto pessoal do tradutor, ou, mesmo, devido a influências culturais e ideológicas sobre o tradutor.

Sintetizando, a análise dos dados mostrou que os Processos Mentais contribuem significativamente para a representação do dinamismo subjetivo da narradora. Também foi identificado que as escolhas tradutórias construíram com um padrão de equivalência ideacional na representação ideacional de Inés, o que não excluiu totalmente escolhas que provocaram mudanças ideacionais que alteraram a imagem que se tem de Inés.

\section{REFERÊNCIAS}

ALLENDE, I. (2006). Inés del alma mia, $1^{\mathrm{a}}$ Ed. Barcelona: Random House.

ALLENDE, I. (2006). Inés de minha alma, $2^{\mathrm{a}}$ Ed. Trad. Ernani Ssó. Rio de Janeiro: Bertrand, 2007.

ARANA, D. B. (2000). Historia general de Chile, 2a . Alicante: Biblioteca Virtual Miguel de Cervantes, v. 1. Disponível em: $<$ http://www.cervantesvirtual.com/obra/historiageneral-de-chile-tomo-primero--0/> Acesso em: 20 de dez. 2015.

ARISMENDI, L. (2006). Mujeres y orden social. El bonor en la construcción de la identidad y de Las prácticas sociales femeninas. Chile 1750-1810. Monografia. Faculdade de Filosofia e Humanidades, Universidade do Chile, Chile.

BAKER, M.; GONZÁLES, L. P. (2013). Tradução e interpretação. In: SIMPSON, J. The Routledge Handbook of Applied Linguistics. Londres e Nova York: Routledge, pp.39-52.

BERBER SARDINHA, T. (2000). O que é um corpus representativo? DIRECT Papers, n. 44 pp.1-26, Disponível em: < http://www2.lael.pucsp.br/direct/DirectPapers44.pdf $>$. Acesso em: 10 out. 2013.

CATFORD, J. C. (1965). Linguistic Theory of Translation: An Essay in Applied Linguistics. Oxford: Oxford University Press.

CANELLO, M. (2008). Isabel Allende entre a arte e o mercado: Inés del alma mía e El Zorro-comienza la leyenda. Dissertação de Mestrado em Letras, Faculdade de Ciências e Letras de Assis. Universidade Estadual Paulista, Assis. 
FUZER. C.; CABRAL, S. R. S. (2014). Introdução à Gramática sistêmico-funcional em língua portuguesa. Campinas: Editora Mercado das Letras.

GHIO, E.; FERNÁNDEZ, M. D. (2008). Lingüística Sistémico Funcional: aplicaciones a la lengua española, $1^{\text {a }}$. Ed. Santa Fé: Universidad Nacional Del Litoral e Waldhuter Editores.

HALLIDAY, M. A. K. (1978). El Lenguaje como semiótica social: la interpretación social del lenguaje y Del signo. Trad. Jorge Ferreiro Santana. México: Fondo de Cultura Econômica, 1982.

HALLIDAY, M. A. K. (1981). Linguistic function and literary style: an inquiry into the language of William Golding's "The Inheritors". In: FREEMAN, D. C. (Ed.). Essays in moderns tylistics. London \& New York: Methuen, pp.325-360.

HALLIDAY, M. A. K. (2001). Towards a theory of good translation. In: E. Steiner \& C. Yallop (Orgs.). Exploring Translation and Multilingual Text Production: Beyond Content. Berlin, Boston: DE GRUYTER.

HALLIDAY, M. A. K.; MATTHIESSEN, C. M. M. (2004). Clause as representation. In:_. An introduction to Functional Grammar, $3^{\text {a }}$ Ed. New York: Ed. Oxford University Press Inc., pp. 168-304.

HALLIDAY, M. A. K.; MATTHIESSEN, C. M. M. (2014). An introduction to Functional Grammar, $4^{\mathrm{a}}$ Ed. London \& New York: Routledge.

HASAN, R. (1989). A framework for the study of verbal art. In: Linguistics, Language and Verbal Art. Oxford: Oxford University Press.

HOY, G. M. V. (2017). Representação da narradora como Experienciadora e Dizente em Inés del alma mía e na tradução para o português brasileiro: uma abordagem sistêmico-funcional. Tese de Doutorado em Linguística Aplicada e Estudos da Tradução.

LIMA, L. O. (2015). Espelbo, espelho meu, existe alguém mais doida ou santa do que eu? Representações para a mulher em crônicas de Martha Medeiros. Dissertação de Mestrado em Letras. Centro de Artes e Letras, UFSM, Santa Maria, RS.

LIMA-LOPES, R. E. (2018). Escolhas Tradutórias Como Sistemas Representacionais: Um Estudo Dos Processos No Conto ‘Amor’ de Clarice Lispector." DELTA: Documentação de Estudos Em Linguística Teórica e Aplicada. 34 (1): 17-39.

LOPES, C. G. (2012). Um olhar sobre a literatura chilena. In: Literaturas americanas. Porto Alegre: EDIPUCRS, pp. 91-104. 
LOVERA, P. M. (1865). Crónica del Reino de Chile, escrita por el capitán don Pedro Mariño de Lovera, reducida a nuevo método y estilo por el padre Bartolomé de Escobar de la Compañía de Jesús. Santiago: Imprenta del Ferrocarril. Disponível em: < http://www.memoriachilena.cl/archivos2/ pdfs/MC0008848.pdf > . Acesso em: 20 de jun. 2015.

MACIEL, A. D. (2007). Gênero e autobiografia na obra de Isabel Allende e Luzilá Gonçalves Ferreiraconsiderações em torno de Meu país inventado, Inés del alma mía e A garça mal ferida. Dissertação de Mestrado em Teoria da Literatura. Centro de Artes e Comunicação, Universidade Federal de Pernambuco, Pernambuco. Disponível em: < http://repositorio.ufpe.br/ handle/123456789/7721 show =full $>$. Acesso em: 10 de nov. 2015.

MONTGOMERY, M. (1993). Language, Character and Action: a linguistic approach to the analysis of character in a Hemingway short story. In: SINCLAIR, J. M., HOEY, M. e FOX, G. (Ed.). Techniques of Description: spoken and written discourse. London e New York: Routledge.

NAVARRO, M. H. (org.). (1995). Rompendo o silêncio: gênero e literatura na América Latina. Porto Alegre: Editora da Universidade/UFRGS.

PERROT, Michelle. (2006). Mi bistoria de las mujeres, $1^{\mathrm{a}}$ Ed., $1^{\mathrm{a}}$ reimpressão. Trad. Mariana Saúl. Buenos Aires: Fondo de Cultura Econômica, 2009.

ROCHA, N. F. F. (2013). Otha que coisa mais linda: As Traduções da Canção Garota de Ipanema em Inglês, Alemão, Francês e Italiano sob a Ótica do Sistema de Transitividade. 153f. Dissertação de Mestrado em Estudos da Tradução. Centro de Comunicação e Expressão, Universidade Federal de Florianópolis, Santa Catarina,. Disponível em: < https:// repositorio.ufsc.br/handle/123456789/107610? show =full $>$. Acesso em: 15 de fev. 2016.

RODRIGUES-JÚNIOR, A. S. (2010). Representação gay em corpus literário paralelo. Revista Brasileira de Linguística Aplicada, v. 10, n. 3, pp. 603-624.

RODRIGUES-JÚNIOR, A. S.; BARBARA, L. (2013). Linguistic Constructions of Appraisal in the Novel The Picture Of Dorian Gray and its Brazilian Translation and Adaptations: an Exploratory Analysis Construções linguísticas de avaliatividade no romance The Picture of Dorian Gray e em sua tradução e adaptações para o português brasileiro: uma análise exploratória. RBLA. v. 13, n. 1, pp. 259-285. Disponível em: http://www. scielo.br/scielo.php? script $=$ sci_arttext\&pid $=$ S1984-63982013000100013. Acesso em 20 de ago. de 2017. 
RODRIGUES-JÚNIOR, A. S.; GARCIA de OLIVEIRA, S. G. de. (2015a). Mudanças Ideacionais das representações linguísticas do heterônimo Álvaro de Campos na obra literária de Fernando Pessoa e em sua tradução para a Língua Inglesa. DELTA. v. 31, n. 2, pp. 391-410. Disponível em: http://www.scielo.br/pdf/delta/v31n2/1678460X-delta-31-02-00391.pdf. Acesso em: 22 de ago. de 2017.

RODRIGUES-JÚNIOR, A. S. (2015b). Contribuições da Linguística Sistêmico-Funcional (LSF) para o entendimento do texto literário em contexto de formação de tradutores. Revista Letras. v. 25, n. 50, pp. 409-420.

SIMPSON, P. (1993). Language, Ideology and Point of View. London \& New York: Routledge.

SONG, Z. (2013). Transitivity analysis of a rose for Emily. Theory and Practice in Language Studies. v. 3, nº 12, pp. 2291-2295. Disponível em: http://www.academypublication. com/issues/past/tpls/vol03/12/20.pdf. Acesso em: 20 de ago. de 2017.

SOUZA, M. M. de. (2006). Querer, pretender, considerar: os processos mentais no gênero editorial. Anais do Evento PG Letras 30 Anos. UFPE: Recife, PE. v. 1, n.1, pp. 457-469.

TONI, C. (2011). O rompimento em Isabel Allende e Ana Maria Machado: as mulberes tecem seu próprio discurso. Dissertação de Mestrado em Letras. Centro de Artes e Letras, Universidade Federal de Santa Maria, Santa Maria. Disponível em: < http://cascavel.cpd.ufsm.br/ tede/tde busca/arquivo.php? codArquivo=3601 > Acesso em: 10 de jan. de 2014 .

YALLOP, C. (2001). The construction of equivalence. In: STEINER, E.; YALLOP, C. (Ed.). Exploring translation and multilingual text production: beyond content. Berlin, New York: Mouton de Gruyter.

Recebido: 16/09/2018

Aceito: 25/02/2019

Publicado: 29/03/2019 